\title{
Examining the effects of background noise on contextualized word learning
}

\author{
Caitlin Alyssa Ross \\ West Virginia University, car0027@mix.wvu.edu
}

Follow this and additional works at: https://researchrepository.wvu.edu/etd

Part of the Speech and Hearing Science Commons

\section{Recommended Citation}

Ross, Caitlin Alyssa, "Examining the effects of background noise on contextualized word learning" (2021). Graduate Theses, Dissertations, and Problem Reports. 8242.

https://researchrepository.wvu.edu/etd/8242

This Dissertation is protected by copyright and/or related rights. It has been brought to you by the The Research Repository @ WVU with permission from the rights-holder(s). You are free to use this Dissertation in any way that is permitted by the copyright and related rights legislation that applies to your use. For other uses you must obtain permission from the rights-holder(s) directly, unless additional rights are indicated by a Creative Commons license in the record and/ or on the work itself. This Dissertation has been accepted for inclusion in WVU Graduate Theses, Dissertations, and Problem Reports collection by an authorized administrator of The Research Repository @ WVU.

For more information, please contact researchrepository@mail.wvu.edu. 
Graduate Theses, Dissertations, and Problem Reports

2021

Examining the effects of background noise on contextualized word learning

Caitlin Alyssa Ross 


\title{
Examining the effects of background noise on contextualized word learning \\ Caitlin A. Ross, M.S. CCC-SLP
}

\author{
Dissertation submitted \\ to the College of Education and Human Services \\ at West Virginia University \\ in partial fulfillment of the requirements for the degree of \\ Doctor of Philosophy \\ in \\ Communication Sciences and Disorders \\ Michelle W. Moore, Ph.D., CCC-SLP, Chair \\ Dennis Ruscello, Ph.D., CCC-SLP \\ Jeremy Donai Ph.D., Au.D., CCC-A \\ Jonah Katz, Ph.D. \\ Department of Communication Sciences and Disorders
}

Morgantown, WV

2021

Keywords: noise, word learning, speech perception

Copyright 2021 Caitlin A. Ross 


\section{ABSTRACT \\ Examining the effects of background noise on contextualized word learning Caitlin A. Ross, M.S., CCC-SLP}

Despite redundancy in the acoustic speech signal, both children and adults demonstrate difficulty listening and learning in noise. Research has shown that the acoustic parameters of classrooms and common study places, such as libraries and coffee shops, are often exposing students daily to unhealthy levels of background noise and distraction as they attempt to access and retain new information. While younger children may encounter new words via deliberate instruction in a classroom setting, older students are more likely to access new vocabulary indirectly via reading or self-study in noisy environments often of their own choosing. In both scenarios, accurate perception of the acoustic signal and minimal auditory distraction is critical to the efficiency of the learning process. Previous studies have examined isolated word learning and some studies have manipulated noise levels. Yet, few, if any, studies have experimentally examined "real-life" noise effects on vocabulary learning when more contextual information is available to facilitate learning. To address this issue, the current study examined vocabulary learning within reading passages in three different listening conditions: multi-talker babble at $45 \mathrm{~dB}$, multi-talker babble at $65 \mathrm{~dB}$, and relative quiet. An impact of the loudest background noise on post-test accuracy was anticipated. Using a pretest/posttest design and manipulating the intensity level of multi-talker babble through noise cancelling headphones, 29 typically hearing college aged participants encountered 18 novel vocabulary words and accompanying engagement activities within the context of reading passages. Word learning accuracy was measured through recall and recognition tasks. Results of mixed modeling analyses showed a significant learning effect from pre-test to post-test regardless of the varying listening condition. Unexpectedly, group averages showed the highest learning on words trained in $65 \mathrm{~dB}$ of background noise. Perhaps the increased noise level enhanced participant focus. An additional model incorporated the different levels of background noise and found no significant effect on the performance accuracy as a function of listening condition. Random effects of participant and word as well as the impact of attention, effort, and training design on learning is also discussed. Better understanding the interaction between noise and learning at all ages is foundational to future work that can optimize hearing assistive technology, the acoustic environment in learning spaces, and improve instructional techniques to create positive language learning environments for students of all levels and abilities. 


\section{Acknowledgements:}

This work was funded in part by a Doctoral Student Research Award from the Grace Clements Communication Sciences \& Disorders Research Endowment of West Virginia University.

Personally, I would like to thank my committee members who stuck with me through the twists and turns of this unique process. Wow. They each demonstrated immeasurable patience with my endless questions.

Thank you to the research participants and CSD professors who made time for recruitment and offered extra credit.

Thank you to the graduate and undergraduate student members of the Language and Literacy Lab who helped with this project and past projects.

A special thank you to Grace Clark at NYU who helped me with Gorilla Software and let me talk shop. I hope I meet you in person one day!

Thank you to The DePaul School for Speech and Hearing in Pittsburgh, PA, for wonderful, thoughtprovoking collaboration on pilot work.

Many thanks to Bambi Liller for allowing me access to the clinical experiences to inform my research and reach my goals both personal and professional. You are an invaluable mentor and a bright part of my West Virginia story.

I owe so much to The River School for an unforgettable externship that encouraged me to take the next step to learn about and advocate for kids with hearing loss.

Thank you to all my hundreds of clients and students: for letting me in, letting me help, and letting me educate. I learned so much from each of you.

Biggest thanks to my family and friends who answered (almost) every phone call, text, and email when I needed to talk out loud about anything other than speech-language pathology.

Dave Koch: I thank you for always thinking I could and would, always finding me, sharing a smile, joke, hug, and picking me up in my low moments. Thank you for caring for me and about me and kinda sorta missing me. I would quite literally be lost without you somewhere in the beautiful Palouse.

Skott Jones: The English language fails me, and I don't have adequate words to thank you, my friend, for encouraging me to slow down, look up, and look within throughout this journey. Thanks for helping me believe in myself, my ability to do hard things, and defining quality mentorship. You said I would want to quit, and you proved you wouldn't let me. You are friendship gold. I am endlessly grateful to have you in my corner.

All my gratitude, deepest love, and appreciation to my Mom, Dad, and sister, Emilie, for letting me go and listening to marathon phone calls when I came up for air and craved connection in the routines of daily life. I continue to benefit from a solid family foundation, curiosity, and encouragement to go "look it up" and try new things. I can ALWAYS count on you and hope I make you proud.

My husband: Thank you for following me literally EVERYWHERE, talking me out of my doubts, and insisting on inside jokes. Thank you for always choosing us, wherever that might lead. My home is where you are, and you remain a special kind of amazing.

My daughter: I simply love you...all the time. You remind me of what is important. You came along halfway through this journey and made it all worthwhile. You are my favorite and I'm blessed every time I hear "Mama". 
Table of Contents

INTRODUCTION

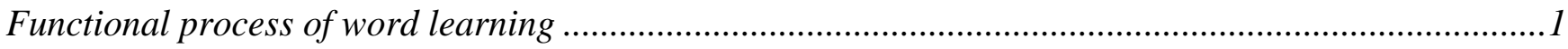

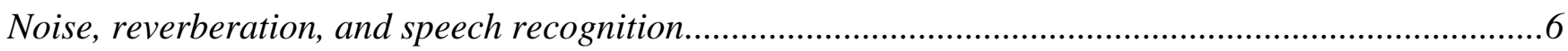

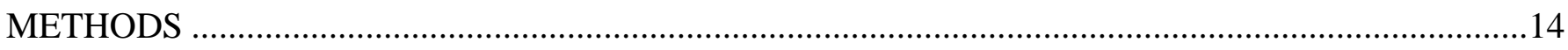

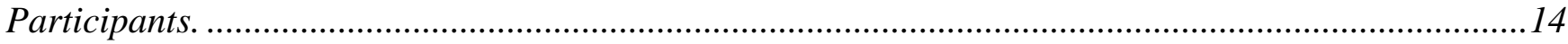

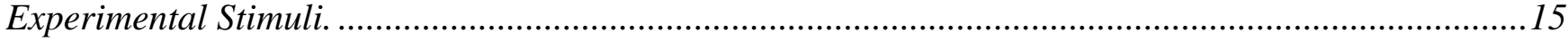

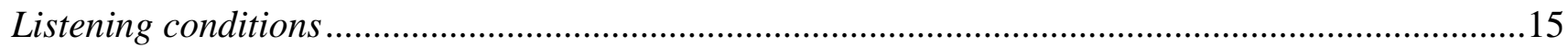

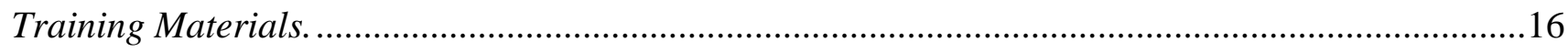

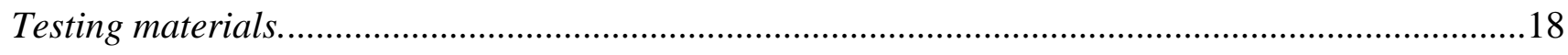

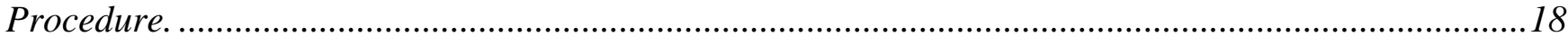

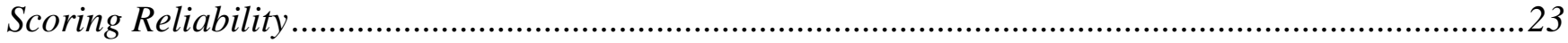

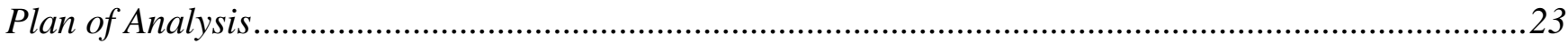

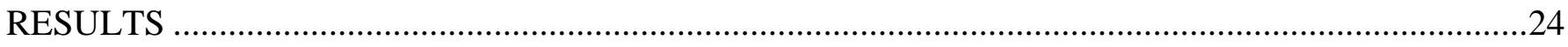

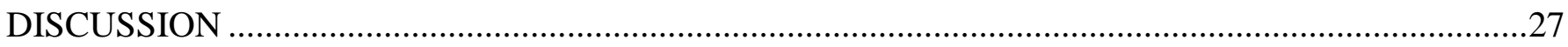

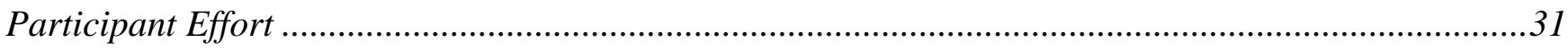

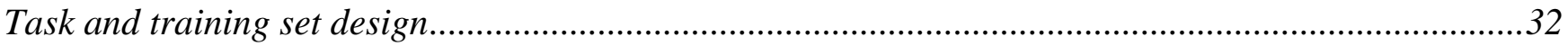

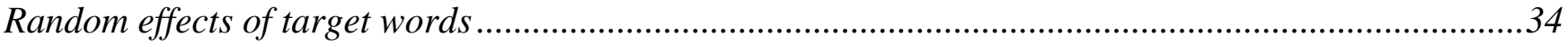

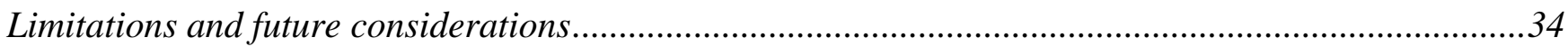

APPENDIX A. GORT-5 Selected Reading Passages ...............................................................36

APPENDIX B. The Flesch Reading Ease Score and Flesch-Kincaid Grade Level ..........................40

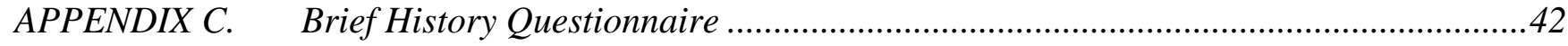

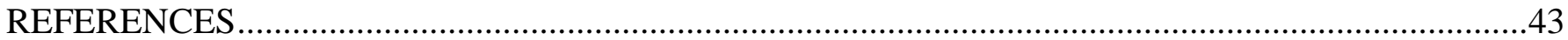




\section{List of Tables}

Table 1. Study session protocol and approximate time for each task …..........................................19

Table 2. Passage Pair and Listening Condition Counterbalancing .......................................................20

Table 3. Means (M) and standard deviations (SD) for participants' ...................................................24

Table 4. Summary of logit mixed-effects model of accuracy from pre-test to post-test (model 1)............25

Table 5. Random intercepts and slopes for target words ........................................................25

Table 6. Summary of logit mixed-effects model of accuracy across listening conditions (model 2).........26

\section{List of Figures}

Figure 1: Example of split screen vocabulary practice activities in an experimental training set as displayed on Gorilla.... 


\section{INTRODUCTION}

When reading or studying independently, which may involve being exposed to new words, older students may attempt to learn in a library, dormitory lounge, or coffee shop setting outside the typical classroom. Much of the background noise found in conventional learning environments such as these will have a speech and environmental noise component. Despite intentional redundancy in the speech signal, students still demonstrate difficulty listening and learning in noisy environments (Plack, 2018). Both auditory and visual perception are important components of the learning process when acquiring new words via reading. There is a paucity of research that has examined the effects of real-life background noise on word learning in adults despite evidence that background noise, learning, and memory may interact dynamically. Few, if any studies have experimentally examined "real-life" noise and on vocabulary learning when more contextual information is provided to facilitate learning. To address this issue, the proposed study will examine contextualized vocabulary learning via reading passages in three different listening conditions among typically hearing college aged students. Better understanding the interaction between noise and learning is foundational to future work that can optimize technology, the acoustic environment, and teaching techniques to create positive, effective, and sustainable learning environments for all learners.

\section{Functional process of word learning}

For the most part, individuals learning language for the first time build their core lexicons incidentally; they learn new words and meanings as they encounter them in everyday routines and conversations. This phenomenon of word learning continues into adulthood, though there have been questions about whether the primary process of acquiring new words differs in adulthood compared to childhood, and more specifically if the involvement of and relationship among the various subcomponents of word learning is different in adults. A functional view of the word learning process entails learning a 
word form, a meaning, and the link between the two (Gupta, 2005). The many subcomponents involved in this otherwise basic formulation include phonological short term and long-term memory, among others.

One way that phonological short- and long-term memory have been studied in word learning is by examining the relationship between word learning, nonword repetition, and immediate serial recall. In word learning experiments, nonword repetition tasks are often selected because the task has been shown to be a strong predictor of language learning in children. A typical nonword repetition task requires verbal repetition of phonotactically legal sound sequences that have no semantic reference. The goal is to measure phonological short-term memory. With immediate serial recall, an individual is given a short list of verbal items presented one at a time. At the end of the presentation, the person is prompted to immediately recall the items in the order in which they were presented. Immediate serial recall has long been seen as the standard verbal short-term memory task. Both immediate serial recall and nonword repetition are tasks that draw on the mechanisms of verbal short-term memory fairly directly. Correlations between nonword repetition, digit span recall (an immediate serial recall task), and vocabulary achievement in children (Gathercole et al., 1992; Gathercole \& Baddeley, 1989, as cited in Gupta, 2003) indicate that the learning of new words is in some way supported by verbal short-term memory. Gupta's (2003) work aimed to address a question from the previous literature regarding whether relationships among nonword repetition, immediate serial recall, and vocabulary achievement also persisted in adults. Looking further into the word learning process in adults, Gupta (2003) proposed a computational model of word learning depicting routes of lexical and sub lexical processing and a sequence memory, or phonological store, that encodes word forms as they are presented to the lexical system. In the model, speech (auditory) input integrates with semantic (visual) input and the phonological store to yield recognizable word forms at the lexical level and output at the sub-lexical level. Given this model, Gupta explained several reasons why the pattern of relationship among nonword repetition, immediate serial recall, and word learning might not be observable in typical adults as it is in children. First, the variation in task performance could be smaller when comparing typical adults to children and thus the correlations 
might be unobservable. Another possibility could be that the pattern, even if significant, would differ greatly from children to adults given adults' increased semantic exposure and long-term phonological knowledge. Differences in vocabulary size may also be present, hence more competition or facilitation. Gupta (2003) conducted two experiments with adults to establish the presence of a relationship among nonword repetition, immediate serial recall (using digit span), and word learning in adults and to show the strength of those relationships. The word learning paradigm included novel words paired with picture referents. Adult participants were given a total of 36 trials split into sets of three nonword-picture pairs. Participants were instructed to listen to the items and repeat them aloud. One item in each set represented the name of an imaginary animal. During presentation of the imaginary animal, a picture of the referent would appear on the screen. After the set of three novel words was presented, the picture of the animal again appeared on the screen, and the participant was cued to label the animal which they had previously learned. Results from this word learning task were correlated with nonword repetition and digit span. Results provided support for the hypothesis that the developmental relationship between digit span and word learning found in children also extends into adulthood. The correlation between digit span and nonword repetition remained significant even when word learning was factored out. Similarly, the correlation between digit span and word learning remained significant even when nonword repetition was factored out, indicating that the dependent measure in the word learning task did not simply measure immediate repetition of the target items. Together, these results indicate that short term memory is involved in word learning for adults, regardless of the fact that adults have more lexical knowledge than children.

Gupta's (2003) word learning study establishes a connection between phonological short-term memory and word learning in adults. Baddeley and colleagues' (2003; 1998) model of working memory helps to further explain how visual input integrates with auditory information in short-term memory so that over time it can be stored in long-term memory. This is relevant to the current study since the word learning paradigm proposed here includes learning of new words from written text. The verbal portion of 
Baddeley's model, the 'phonological loop', is composed of the phonological store, used for the short-term storage and manipulation of acoustic information, and a subvocal rehearsal mechanism, the articulatory system, to refresh information in the phonological store as it decays over time. The model depicts pathways for both visual and auditory input and shows that auditory input has a direct path to the phonological store without involvement from the articulatory system (though subvocal rehearsal is still needed to prevent decay). Visual information (i.e. written text), on the other hand, is fed into the articulatory system where subvocal rehearsal connects a priori phonological knowledge with the orthographic input which then can be processed in the phonological store. Baddeley's work reminds us that the process of reading to learn new words, while it involves visual (orthographic) input, still involves the phonological memory system routed through subvocal rehearsal. Thus, it is reasonable to posit that learning in noise could disrupt the process and language learning outcomes could be negatively affected. Another salient example emphasizing the orthography-phonology interaction in word learning comes from Ehri (2014). When one encounters printed text, orthographic mapping involves the activation of grapheme-phoneme connections to commit new words to memory. According to Ehri, vocabulary learning is facilitated when orthography accompanies pronunciations and meanings of new words. Visual input (i.e. written text) of a word form can activate pronunciation (phonology) and meaning in short term memory and allow readers to focus attention on comprehension rather than mere recognition. These audiovisual connections can accelerate the processing of phonological constituents into long-term phonological memory for words. There are two implications for Ehri's claims to the current study. First, encouraging the strategy of pronouncing novel words aloud when reading silently activates orthographic mapping and helps build the lexicon. As such, participants in the current study will be prompted to read the target words aloud as part of the planned engagement activities surrounding the target words. Second, the audiovisual connections again reinforce the previously stated idea that word learning through reading could be disrupted from noise in the environment, which will be directly examined in the current study. 
In another paper examining the various processes involved in word learning, including supplemental instruction, Adlof (2019) reviewed evidence of some of the differences present for different age groups. This prologue provided an overview of the importance of vocabulary development or word learning to eventual literacy and academic achievement including examples for preschoolers, school-age, adolescents, and college students who are still encountering new words and developing vocabularies. In a study with young adults, Adlof et al. (2019) described the development of DictionarySquared, a webbased platform which provides tailored vocabulary instruction to high school students using a combination of dictionary definitions, contextual examples, and active processing activities. A randomized control trial measured word learning from students assigned to use the program as part of class versus students receiving regular instruction on vocabulary words. Results yielded significant learning of trained words, but no significant generalization of learning. In other words, students were able to learn the words they were directly taught via the program, but carryover to other untaught words was minimal. Additionally, McGregor, Marshall, Julian, and Oleson (2019) conducted a randomized control trial of Vocabulary.com usage by students preparing for the Graduate Record Examination (GRE). College students assigned to the treatment group were instructed to use the program for 20 minutes, 4 days a week for 1 month. Participant data showed that approximately half of the students completed the program for the required number of minutes (320 total), and that those who used the program more often achieved mastery of more words. However, upon further analyses there was no significant difference in the GRE scores of the treatment group versus the control group again suggesting minimal generalization of skills. Despite low evidence of skill generalization, both studies show direct benefits to overall direct word learning when using more interactive techniques and repetition. The proposed study plans to build off the authors' usage of context and engagement activities to help facilitate learning.

Taken together, the previous research supports the essential role of both visual and auditory input in effective and sustainable word learning. Even when learning is occurring via written text, auditory and visual perception are important components of the word learning process. Accurate perception of an 
acoustic speech stream (i.e. auditory perception) is critical to processing a phonological form and attaching meaning to a spoken word. Visual perception and subsequent subvocal rehearsal can activate phonological representations in short term memory and aid in learning. One remaining question is whether background noise that is often present in natural word learning contexts influence these processes. The impact of noise on word learning will be reviewed in the next sections.

\section{Noise, reverberation, and speech recognition}

Learning new vocabulary is a daily activity (particularly in younger children) that often occurs in noisy environments such as the classroom. Two parameters that are measured to judge classroom acoustics are signal to noise ratio (SNR) and reverberation. Noise refers to any unwanted sound, generated both outside and inside the classroom, that interferes with listening and reception of speech. Reverberation is caused by the persistence of sound as it is reflected off hard surfaces. Reverberation time (RT) is the time taken for a sound to decay by $60 \mathrm{~dB}$ from its original intensity. Excessive reverberation has a marked, negative effect on speech intelligibility by smearing or masking sound. In particular, the weaker, high frequency consonants, crucial for speech intelligibility, will be masked by the stronger, lower frequency vowels (Nabalek \& Nabalek, 1985). Research findings recommend a classroom SNR of at least $+15 \mathrm{~dB}$ for the intelligible reception of speech (i.e., the teacher's voice should be $15 \mathrm{~dB}$ more than the background noise), limiting classroom background noise to 35-40 $\mathrm{dB}$ and reverberation time between 0.6 and 0.7 seconds (Finitzo-Hieber \& Tillman, 1978). This study focused largely on the effects of background noise only. Despite what is recommended in the literature, it was found that the typical noise level in occupied classrooms is 60-65 dB including environmental noises such as HVAC systems and traffic noise, speech noise, and student-generated noise such as side conversations and papers shuffling (McSporran, 1997). Typical classroom SNRs range between - 7 and $+4 \mathrm{~dB}$, and are frequently $0 \mathrm{~dB}$ (Berg, 1993). Research has found typical levels of reverberation ranging from 0.3 to $>1.5 \mathrm{~s}$ (Berg, 1987). 
In conclusion, many classrooms often exceed recommended levels of noise and reverberation which could lead to problems listening and learning for students.

Although the bulk of the research on classroom noise has been conducted during elementary education, lecture halls and college classrooms are also subject to poor acoustics; thus, older students are often learning in less than ideal conditions as well. Additionally, older students may not think of the impact of noise and can often be found in noisy learning environments sometimes of their own choosing. When reading or studying independently, which may involve learning new words, older students may attempt to learn in a library, dormitory lounge, or coffee shop. However, these settings could be problematic because many different environmental noises can impact focus and learning (e.g., speech noise, machine noise, etc.).

Much of the background noise found in conventional learning environments such as classrooms and lecture halls and sought-after study environments such as coffee shops and libraries will have a speech and environmental noise component. In these situations, it is important to consider the possible impact of informational masking. For most people, hearing speech is usually effortless and efficient. We are able to perceive a sufficient proportion of the speech sounds for comprehension of the speech signal. Frequently, however, a speech signal will be masked by noise (i.e., sounds other than the voice of the person we are trying to hear). Noise can interfere with accurate perception of the speech signal in two ways. First, the noise can physically interfere with the speech signal (i.e., outside of the perceiver, in the acoustic environment). This is often referred to as energetic masking (Pollack, 1975). Second, the noise can perceptually interfere with the speech signal (i.e., inside the perceiver, in the perceptual process). This is often referred to as informational masking (Pollack, 1975; Watson et al., 1976). Environments where competing speech is present, like a classroom, often result in some level of informational masking of the target signal such as the teacher. Attention and focus can also be compromised by a high level of masking. (Hoen et al., 2007; Lidestam et al., 2014; Wightman \& Kistler, 2005). This may explain why competing 
speech or music with words may be more disruptive than environmental noise to an individual's ability to learn.

Speech, because of its instantaneous nature, can easily be missed in poor acoustic conditions (McSporran, 1997). For example, Kenyon, Leidenheim, and Zwillenberg (1998) used cafeteria noise comprising a substantial speech component and measured speech recognition and discrimination in adults with and without sensorineural hearing loss. Average speech discrimination accuracy decreased over 5\% in the presence of noise for the typically hearing group, and over 33\% for the hearing-impaired group. When speech recognition thresholds were considered, it was found that those with higher speech recognition abilities demonstrated greater loss of speech discrimination in noise. Early research also looked at the types and levels of noise in libraries. McDiarmid and Tatum (1938) investigated the types and measurement of library noise by industry standards at the time. They defined noise as "irregular sound impulses audible to the human ear" and "a medley of unusual sounds; sound out of place" (p. 201). The authors classified the types of noise encountered in a university library as either background noise (i.e., constant noise derived from library location, ventilation, and machines) or service noise (i.e., intermittent noises from individuals using the library). They compared the intensity and disruption of the noise level to a functional conversation level of $60 \mathrm{~dB}$ and found that most background noise was of little consequence, but that many service noises measured louder than typical conversation. While the study is not experimental in nature and did not report the effect of certain noise levels on the accuracy of a learning outcome, this study acknowledges the library environment as a noisy one and discusses the impact of noise on a library's function, in addition to describing ways noise might be decreased. In general, this article supports the idea that disruptive noises exist in daily study and learning environments often perceived to be quiet.

In fact, the literature contains numerous studies showing that noise impacts speech recognition, or the ability to perceive and detect an audible sound as known or unknown speech. For example, classroom noise, which is partly dependent on the acoustics of the building and its proximity to outside 
environmental and traffic noise, has been used in speech recognition studies involving children. Jamieson, Kranjc, Yu, and Hodgetts (2004) recorded the actual noise in an occupied elementary classroom for use in their study of speech understanding (i.e. speech recognition) in varied noisy environments by 5- to 8-year old children. Participants were separated into grade levels and tested individually in an otherwise quiet classroom. It was found that performance accuracy among the younger ages was more sensitive to higher levels of noise and had less favorable SNRs. At -6 dB SNR, the scores for kindergarten and grade 1 children declined precipitously, while those for grades 2 and 3 children remained high until they encountered the very unfavorable $-12 \mathrm{~dB}$ condition. This significant difference in scores suggests that while older (grade 2 and 3) children can tolerate intermediate (-6 dB SNR) levels of noise, younger (kindergarten and grade 1) children cannot. Children of all ages were significantly affected by high levels of noise.

Wróblewski, Lewis, Valente, and Stelmachowicz (2012) also assessed the speech recognition of typical hearing children and young adults in three virtual listening environments with varying degrees of noise. The authors found that speech recognition decreased in the noisier, reverberant conditions and with decreasing age. The results of this study reveal systematic developmental changes in speech recognition in noisy and reverberant environments for elementary-school-aged children. Further, the results indicate that younger children require better acoustic conditions to achieve sentence recognition equivalent to their older peers and adults. These findings are consistent with work done by evaluating speech recognition, comprehension, and sentence completion in children and adults (Fallon et al., 2000; Neuman et al., 2010; Stelmachowicz et al., 2000). Taken together, the results support the importance of minimizing noise in classrooms, further document the negative effects of extraneous classroom noise, and reveal an overall improvement in performance with increasing age. It has been suggested that children do not achieve adult levels of competence in noisy or reverberant conditions until the age of 13-15 years (Elliot, 1979). Other factors may also contribute to better performance with age such as a larger vocabulary, more exposure to language in general, greater cognitive flexibility, and greater ability to use context (e.g., previous 
syntactic and semantic clues). However, it is important to note that, while speech recognition in noise is improved with age, recognition accuracy in adults still is negatively impacted within listening conditions (Fallon et al., 2000; Neuman et al., 2010; Stelmachowicz et al., 2000; Wróblewski et al., 2012). Further, although it makes sense that word learning would be a challenge when there is poor speech recognition, it is important to note that studies of speech recognition in noise do not entirely inform the impact of learning in noise. Speech recognition tasks differ from word learning tasks in that they do not provide support like repetition, cues, multiple exposures, or other context clues that could facilitate learning and understanding of a new word. Thus, it is critical to evaluate the impacts of noise on word learning tasks for both children and adults.

Noise is an unavoidable part of many real-life, daily environments and there are many open questions regarding the impacts and effects of differing types of noise on learning in adults. The coffee shop environment, in particular, can be fraught with competing types of unpredictable background noise which may influence the cognitive processes involved in effective learning. Despite the music, machine noise, and conversational noise, coffee shops often double as a study setting where speech recognition and attention to task is challenged by distractions and disruptions. However, there is limited research examining learning in this setting.

\section{Learning and noise}

The bulk of the literature looking at cognitive processing and learning in noise has used artificial noise or has manipulated noise level or volume rather than type. For example, Han, Storkel, and Cox (2012, 2016) examined stimuli mixed with broadband white noise at two different SNRs and found that noise heavily taxed cognitive processes (e.g., working memory) in college-aged adults. Specifically, under a taxing condition such as noise, adults may require a convergence of cues similar to that observed for children (Hoover et al., 2010; Storkel et al., 2006). 
In another example, Nielsen (2015) showed that effects of noise depended on the type of cognitive task completed. Nielsen conducted two studies regarding the impact of ambient noise on cognitive flexibility, or the mental ability to switch between thinking about two concepts and to think about multiple concepts simultaneously and learning in undergraduate students. Across three creative tasks, the first study demonstrated that creativity can be enhanced by moderate volumes of ambient noise, particularly among older students who listen to music while they study/work. The second study examined how noise affected performance on a category learning task designed to measure cognitive flexibility. Participants were tested in pairs and each pair was randomly assigned to one of three noise volume conditions: control (quiet), medium, or high volume. Participants were told that they would be shown images of crystal balls and they were to indicate, by button press, if the balls belonged to a blue or green wizard. Participants were not given any further instructions on how to make the choices, rather they were provided feedback after each trial with the intent that they would eventually learn how to complete the task by relying on the feedback. Results showed that category learning using this paradigm was neither enhanced nor impaired by the ambient white noise. In short, this work suggests that background noise may be beneficial for creativity but is neither beneficial nor detrimental for certain types of learning. While these studies have been informative in regard to learning and noise, the following studies that will be discussed more directly address the impact of noise on language-based learning tasks.

Dockrell and Shield (2006) explored the effects of typical classroom noise on the performance of elementary children on verbal literacy and speed tasks. Participants were randomly assigned to one of three listening conditions: speech background noise, speech background noise plus environmental sounds, and quiet. A differential negative effect of noise source on type of task was observed. Children in the speech plus environmental listening condition performed significantly worse than those in the quiet and speech only conditions on speed of processing tasks. In contrast, performance on verbal language tasks was significantly worse in the speech only condition. 
In another set of studies, Klatte, Lachmann, and Meis (2010) and Klatte, Hellbrück, Seidel, and Leistner (2010) manipulated noise levels and degrees of reverberation in a simulated classroom setting for children in order to examine the impact of noise on various language tasks. Analyses of these field studies found significant effects of reverberation on speech perception and short-term memory as measured by decreased performance accuracy on sentence comprehension and single word identification. Additionally, children from classrooms with longer reverberation times performed lower on phonological processing tasks overall, including 'odd-one-out' trials where participants were required to identify which item did not belong based on grouping the initial or final sounds of a set of targets. A later study by Klatte, Bergstroem, and Lachmann (2013) evaluated noise effects on the cognitive performance of children compared to adults. Both of these studies found that children require more favorable noise levels and facilitative contexts to achieve similar performance accuracy to their adult counterparts; however, while adults can often use contextual cues due to years of semantics and prior language exposure, they are still impacted by noisy environments.

Directly related to word learning in noise, Riley and McGregor (2012) examined children's word learning in response to more and less perceptible acoustic signals. They asked whether noise disrupts expressive word learning and whether use of a clear speech style ameliorates that disruption. Typically hearing 9- and 10-year-old children attempted to learn two sets of eight novel words and their referents. Authors simulated problematic background noise by introducing broadband white noise during the training of half of the participants. Participants heard all the words 13 times each within meaningful narrative discourse. Signal-to-noise ratio (noise vs. quiet) and speech style (plain vs. clear) were manipulated such that half of the children heard the new words in broadband white noise and half heard them in quiet. Children who were trained in quiet learned to produce the word forms more accurately than those who were trained in noise. Clear speech resulted in more accurate word form productions than plain speech, whether the children had learned in noise or quiet. Learning from clear speech in noise and plain 
speech in quiet produced comparable results. Despite using novel words, this research suggests that noise limits expressive vocabulary growth in children, reducing the quality of word form representation in the lexicon. Clear speech input, perhaps serving as facilitative context, can aid expressive vocabulary growth in children, even in noisy environments.

A final point to consider is the learning context. Many studies have addressed word learning in children and/or adults at the single word level. However, the cognitive and linguistic processes involved in the perception of words in a sentence or passage context are quite different from those involved in the perception of isolated words because of the availability of syntactic, semantic, and pragmatic information, which is not available from isolated syllables or words (Bradlow et al., 2003). The advantage of words in sentences over words in isolation when presented in a noisy environment was originally demonstrated by Miller, Heise, and Lichten (1951) who interpreted this result as stemming from the fact that access to the contextual information provided by the sentence helps the listener by narrowing the response alternatives. To this point, the benefits of an interactive learning style have been studied extensively in children, showing that preschoolers through middle school children especially rely on context, a dialogic reading style, and supplemental engagement activities to best learn and retain new words (Beck et al., 2013; Coyne et al., 2004; Justice, 2002; Justice et al., 2005). Less is known, however, about the extent that context facilitates new word learning in adults. Much of the adult research has focused on word learning in isolation, or using novel words, rather than a more natural scenario such as real words in narrative context. Although Storkel, Armbrüster, and Hogan (2006) measured adult word learning (recognition and production) after differing amount of exposures in a story context originally created for child participants in an earlier study, their study was focused on the effects of lexical features (phonotactic probability and neighborhood density) rather than the impact of various listening conditions. Thus, the impact of real-life environmental noise on word learning in a written narrative context remains an important question to consider when looking at learning outcomes in adults. To that end, the current study 
will use written passages in the word learning paradigm with two volumes of multi-talker babble plus relative quiet as listening conditions.

As shown, several studies examining word learning in adults have manipulated noise as a variable, yet artificial noise level is commonly created rather than incorporating 'real-life' noise. Also, target words are often presented in list or sentence form rather than embedded within narrative context with accompanying engagement activities. To address these gaps, the present study proposes to investigate the impacts of real-life noise (e.g., coffee shop noise) on the contextualized word learning of adults. Specifically, the research question that will be addressed is: What is the effect of background noise on adults' novel word learning ability when reading narrative passages? It is hypothesized that the louder multi-talker babble will have the most detrimental effect on vocabulary learning given the body of literature reviewed that shows effects of noise during learning tasks (e.g., Crandell \& Smaldino, 2000; Dockrell \& Shield, 2006; Fallon et al., 2000; Finitzo-Hieber \& Tillman, 1978; Han et al., 2012; Jamieson et al., 2004; Kenyon et al., 1998; Klatte, Lachmann, et al., 2010; Maxwell \& Evans, 2000; Nelson et al., 2003; Neuman et al., 2010; Picard \& Bradley, 2001; Riley \& McGregor, 2012; Stelmachowicz et al., 2000; Yacullo \& Hawkins, 1987).

Investigating the potential impact of noise on the learning process in adults may point towards more realistic expectations for student learning at all levels. Also, identifying the intricacies of the noise and word learning relationship may be particularly important in future work that can optimize technology, the acoustic environment, and teaching techniques to create positive, effective, and sustainable learning environments for all learners, including children and adults with diagnosed hearing impairment.

\section{METHODS}

Participants.

Following approval by the University's institutional review board, a total of 29 college-age participants were recruited via Communication Sciences \& Disorders (CSD) courses and word of mouth. 
Participants included monolingual undergraduate students in CSD courses between the ages of 18 and 22 $(M=19.34, S D=1.20)$ with no history of speech, language, hearing, or cognitive deficits as documented via self-report on a questionnaire administered on the day of the study session. The participants selfreported having no vision difficulties not correctable with glasses and passed a pure-tone hearing screening at $20 \mathrm{~dB}$ for 500, 1000, 2000, and $4000 \mathrm{~Hz}$. Because the experimental task involved reading, word recognition was screened using the Word Identification and Word Attack subtests of the Woodcock Reading Mastery Tests, Third Edition (WRMT-III; Woodcock, 1997). These two subtests comprise the Basic Reading Skills composite score which has a normative average of 100 and a standard deviation of 15. On average participants scored within $1 S D$ of the normative average $(M=93.21$ and $S D=6.65)$. Participants who were eligible earned extra credit via the department-approved extra credit policy upon completion of the study.

\section{Experimental Stimuli.}

Listening conditions. To evaluate the effects of ambient noise on word learning, three listening conditions were considered: multi-talker babble at an intensity of $45 \mathrm{~dB}(\mathrm{~A})$, multi-talker babble at an intensity of $65 \mathrm{~dB}(\mathrm{~A})$, and artificially attenuated noise (i.e., silence with noise cancelling headphones) as the control. The speech background listening conditions were 20 -talker babble modeled after ambient 'coffee shop' noise as noted in previous research (Crandell \& Smaldino, 2000; Jamieson et al., 2004; Nielsen, 2015; Picard \& Bradley, 2001; Riley \& McGregor, 2012). The multi-talker babble was played through circumaural headphones, and the sounds were calibrated to the intensity levels used in the experiment using slow analysis and dB (A) weighting with a Larson Davis 824 sound level meter.

Using Audacity (version 2.1.2), two tracks of multi-talker babble were created, one for each listening condition. For passages that were presented during the background noise conditions, the noise was played the entire length of time that the passage and the related engagement activities were on the screen. All participants wore noise-canceling headphones throughout the experiment, even when reading 
under the quiet condition to ensure treatment fidelity. All noise was presented at a uniform volume through the headphones and controlled by the researcher. Biological checks were conducted prior to each participant session to verify the implementation of these procedures.

Training Materials. The six reading passages used in the study were taken from the Gray Oral Reading Test, Fifth Edition (GORT-5; Wiederholt \& Bryant, 2012). This is a standardized oral reading measure normed for individuals up to 23 years old that includes short passages increasing in complexity. The GORT-5 includes 26 stories total, divided equally between Form A and Form B. The stories selected for this study were the highest-level stories in both forms that are appropriate for college-level students. Per the manual, several steps were taken to "ensure that the stories are appropriate for student readers... and that the vocabulary selected for each story was appropriate for each grade level" (Wiederholt \& Bryant, 2012, p. 56). To further ensure advanced comprehension levels, both the Flesch Reading Ease and Flesch-Kincaid Grade Level (https://goodcalculators.com/flesch-kincaid-calculator/) were calculated on the six highest reading passages (three from each form). Per the calculations, all but one of the selected passages are rated above the participants' anticipated grade level, so that some of the words within the passages are less likely to be familiar to participants and can serve as target words for the word learning paradigm. Three words were selected per passage and two short passages were grouped into each training set for a total of six target words per set. Understanding of the general content of the passages was verified during the testing session by administering three of the brief reading comprehension questions included in the GORT-5 at the end of each passage. A description of the Flesch-Kincaid measures, their equations, a score table, and results for each individual passage in the study are included in Appendix A.

Stimuli selection was based on the three-tiered framework for vocabulary instruction as outlined in Beck et al. (2013), and briefly explained here. The first tier consists of the most basic words that a child would encounter: dog, ball, tired, run, look, stop, come, talk, etc. These are words typically heard in daily, 
oral conversations and people are exposed to them at a high frequency from an early age. Tier two contains words that are of high utility to mature language users and found across a wide variety of domains. Examples include contradict, fervent, auspicious, retrospect, and circumstances. These words occur less frequently in conversation, which means that students are less likely to acquire or learn these words independently without reading or deliberate instruction. Lastly, some examples of words in tier three might be considered discipline specific such as filibuster or epidermis (Beck et al., 2013). Beck et al. go on to explain that words in tiers one and three warrant less deliberate instruction in school either due to high frequency exposure and everyday use in conversation (tier 1) or due to a low frequency of use limited to specific topics and disciplines (tier 3). Thus, it is tier two words that most often warrant deliberate instruction. In order to be selected for the current study, words met the categorization of a tiertwo word and were chosen from the high-level passages described above. Another factor considered when selecting target stimuli was the surrounding supportive context available in the passage. A target word was selected if there was little to no supportive context explicitly written in the passage as to the meaning of the word such as a synonym. The decision to use six words per pair of passages is supported in part by previous work looking at the impact of dose and frequency on word learning by students (Beck et al., 2013; Justice et al., 2005; Storkel et al., 2019). Too many words, and thus pauses for elaborations, may negatively impact the flow of the passage and ability of the participants to comprehend what they are reading.

A list of 37 tier-two words occurring in the GORT-5 passages was piloted with 23 CSD freshmen and sophomore students who did not participate in the study. The students were asked to define each of the 37 words without using the aid of dictionaries or any outside resources. According to pilot data, all 18 target words selected for the study fell below $45 \%$ accuracy with the exception of potentates (55\% accuracy among the pilot group), were at least 3 syllables in length, and did not occur in the same sentence as another target word. Overall, the pilot data yielded an average accuracy of $20.22 \%$ and a 
range from 0\%-54.6\% accuracy across the 18 target words. The final list of target stimuli used in the experiment and their pilot accuracy data are included in Appendix B.

Testing materials. Pre- and post-testing included a recall task presented on a laptop via the Gorilla Experiment Builder platform (www.gorilla.sc; Anwyl-Irvine et al., 2019). The 18 target words were presented in writing on the screen one at a time in random order and participants were instructed to type a brief definition of the target word in a text box displayed below. All participants were encouraged to provide a definition for each word even if they needed to guess. The font type, size, and color were uniform for all written presentations.

\section{Procedure.}

At the time of recruitment and prior to consent, potentially eligible participants were made aware of the goals of the research program, purpose and motivation, benefits and risks to participation, task expectations, and time requirements.

All study sessions took place in an unoccupied classroom on West Virginia University's campus, and all COVID-19 policies and protocols required by the University were strictly followed. Both participant and researcher wore a mask throughout all activities and maintained social distance. The testing room was equipped with a plexiglass divider between researcher and participant. Minimal to no physical contact was necessary throughout the duration of the procedure. Spoken responses throughout the study session were recorded via a Sony digital handheld recorder for later review by the researcher to help with scoring. All equipment and materials (e.g., headphones, microphone, etc.) were thoroughly sanitized before and after each use.

Recruited participants first completed a brief history questionnaire (See Appendix C) and then were screened for hearing acuity at $20 \mathrm{~dB}$ using a hand-held audiometer. Following completion of the hearing screening, participants completed the pretest and training components of the experimental procedure. Participants were seated directly in front of the laptop and used noise cancelling headphones throughout 
the experimental tasks while they read short passages and engaged with target vocabulary words.

Performance accuracy was measured once at the comprehensive pre-test (i.e., all target words tested) and in a comprehensive post-test comprising all the target words. The pre-test and post-test were administered in relative quiet (i.e., wearing noise cancelling headphones but without either of the background noise listening conditions). Standardized testing using two subtests of the WRMT-III was administered following the three experimental training sets and prior to the comprehensive post-test. The order of study session tasks and approximate time to complete each task are presented in Table 1 and are described in further detail below.

Table 1. Study session protocol and approximate time for each task

\begin{tabular}{|l|c|}
\hline Tasks (in order) & Duration \\
\hline Questionnaire/Hearing Screening & $5 \mathrm{~min}$ \\
\hline Pretest for all target stimuli & $10 \mathrm{~min}$ \\
\hline Experimental Training - Set 1 (passages/listening conditions semi-counterbalanced) & $10 \mathrm{~min}$ \\
\hline Experimental Training - Set 2 (passages/listening conditions semi-counterbalanced) & $10 \mathrm{~min}$ \\
\hline Experimental Training - Set 3 (passages/listening conditions semi-counterbalanced) & $10 \mathrm{~min}$ \\
\hline SHORT BREAK (optional) & \\
\hline WRMT-III Subtests: Word Identification and Word Attack & $5 \mathrm{~min}$ \\
\hline Posttest for all target stimuli & $10 \mathrm{~min}$ \\
\hline TOTAL & $60 \mathrm{~min}$ \\
\hline
\end{tabular}

For the pre-test and posttest, participants were tested on all target vocabulary words using a recall task in which each target word appeared and remained on the screen paired with a text box in which the participant was asked to type a brief definition. While there were 36 total possibilities of story presentation order combined with listening condition order for the training phase of the word learning paradigm, for feasibility of administration order of passage presentation and order of listening condition were semi-counterbalanced separately across participants. Each passage pair was first, second, and third anywhere from 8 to 12 times for each position and each listening condition was first, second, and third anywhere from 5 to 12 times for each position. Each passage pair was presented under each listening condition anywhere from 8 to 12 times (see Table 2). 
Table 2. Passage Pair and Listening Condition Counterbalancing

\begin{tabular}{|c|c|}
\hline Condition & Number of participants \\
\hline \multicolumn{2}{|l|}{ Passage Pair Order } \\
\hline Pair 1 > Pair $2>>$ Pair 3 & 6 \\
\hline Pair 1 > Pair 3 >> Pair 2 & 6 \\
\hline Pair 2 >> Pair 1 >> Pair 3 & 5 \\
\hline Pair 2 >> Pair 3 >> Pair 1 & 4 \\
\hline Pair 3 >> Pair 1 > Pair 2 & 4 \\
\hline Pair $3>>$ Pair $2>>$ Pair 1 & 4 \\
\hline \multicolumn{2}{|l|}{ Listening Condition Order } \\
\hline Quiet $>>45 \mathrm{~dB}>>65 \mathrm{~dB}$ & 6 \\
\hline Quiet $\gg>65 \mathrm{~dB} \gg>45 \mathrm{~dB}$ & 6 \\
\hline $45 \mathrm{~dB} \gg>65 \mathrm{~dB} \gg>$ Quiet & 6 \\
\hline $45 \mathrm{~dB}>>$ Quiet $>>65 \mathrm{~dB}$ & 6 \\
\hline $65 \mathrm{~dB} \gg>$ Quiet $\gg 45 \mathrm{~dB}$ & 3 \\
\hline $65 \mathrm{~dB} \gg>45 \mathrm{~dB} \gg$ Quiet & 2 \\
\hline \multicolumn{2}{|l|}{ Passage Pair 1} \\
\hline Quiet & 9 \\
\hline $45 \mathrm{~dB}$ & 8 \\
\hline $65 \mathrm{~dB}$ & 12 \\
\hline \multicolumn{2}{|l|}{ Passage Pair 2} \\
\hline Quiet & 10 \\
\hline $45 \mathrm{~dB}$ & 10 \\
\hline $65 \mathrm{~dB}$ & 9 \\
\hline \multicolumn{2}{|l|}{ Passage Pair 3} \\
\hline Quiet & 10 \\
\hline $45 \mathrm{~dB}$ & 11 \\
\hline $65 \mathrm{~dB}$ & 8 \\
\hline
\end{tabular}

Each training set consisted of silently reading two passages and learning three emboldened target vocabulary words occurring within each passage, for a total of three training sets, six passages, and 18 target words. Following the pre-test, written instructions for the training phase of the experiment were presented on the screen. Participants were informed that the target words would be presented in the following passages. They were instructed to read the passages carefully and engage in brief activities with the target words via the laptop. When ready to begin the first training set, they clicked a button to elicit the first set of passages. The passage text appeared on the screen for participants to read silently as multitalker babble was presented through headphones for two of the three experimental conditions. Participants 
wore the headphones for the duration of the training phase (i.e., during all three training sets including the 'quiet' condition) to maintain the same procedure for all passages.

To facilitate word learning during the training phase, embedded elaborations and engagement activities were incorporated into the passage readings. Target word selection, embedded elaborations, and engagement activities were modelled on previous research done by Justice and colleagues (Justice, 2002; Justice et al., 2005) and the three-tiered framework for vocabulary development by Beck and colleagues (2013) which includes and encourages a variety of ways to engage further with target words in context. Clinical trials and meta-analyses show strong replicable evidence that an interactive instructional style with contextual activities has moderate to large effects on word learning among typically developing children (Coyne et al., 2004; Flack et al., 2018; Marulis \& Neuman, 2013; Mol et al., 2008) and adult learners (Gaskell \& Dumay, 2003; Han et al., 2016; Storkel et al., 2006). As such, during the training phase of the paradigm, the target words were emboldened as they occurred within the text. Participants were instructed to pause their reading when they encountered an emboldened word and click on the button labeled with that word to view a split screen display with vocabulary practice specific to that word. In addition to a dictionary definition, each target word was used in a sentence and four possible synonyms were provided for review before continuing with the passage text. It is important to note that the 'noise' in the experimental conditions was played throughout these brief engagement activities. See an example script for an encounter with a target word below. 
Figure 1: Example of split screen vocabulary practice activities in an experimental training set as displayed on Gorilla

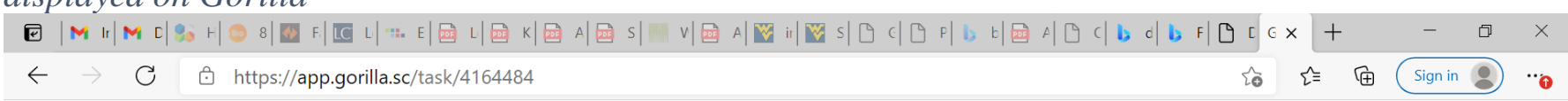

Vocabulary Practice

Story 1

In the spacious expanse of Western territory, consequently, we perceive an abundant theater for hostile pretensions, without any arbitrator or common judge to interpose between the contending factions. To deduce from the past to the future, we shall have excellent ground to apprehend that the sword would occasionally be appealed to as the arbiter of their disagreements. The circumstances of the dissention between Connecticut and Pennsylvania respecting the terrain at Wyoming, admonish us not to be sanguine in expecting a straightforward accommodation of such differences. The Articles of Confederation obliged the parties to submit the matter to the resolution of a federal judiciary. The submission was completed, and the court decided, after careful contemplation and deliberation, in favor of Pennsylvania. B determination; nor did she appear to be entirely resigned to it, until, by deterition the grievance she supposed herself to have sustained. Nothing here said is intended to convey the slightest censure of the demeanor of that State. She no doubt sincerely considered herself to have been victimized by the pronouncement: and States, like individuals acquiesce with enormous reluctance in determinations to their disadvantage.
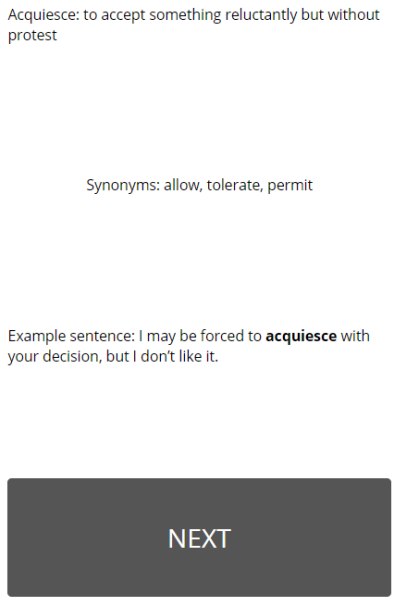
. 
for the second set, and so on through the three training sets. After the three training sets were completed, there was the opportunity for the participant to take a short break, if needed. Then, the participants removed their headphones and completed the subtests from the WRMT-III.

Finally, participants completed the final experimental task, a comprehensive post-test comprising all 18 target words. This final post-test was also presented via Gorilla in the same manner as the pre-test in which the target words were randomly presented one at a time and participants were asked to type a brief definition of the target word displayed on the screen.

Scoring Reliability Interrater reliability measures were obtained for judgments of accuracy in participants' experimental pre- and post-test responses. A graduate research assistant independently scored tasks for interrater reliability using the participants' compiled data and a scoring key generated by the researcher. Six participants (20\% of the sample) were randomly selected. Interrater agreement for judgment of correctness was $98.1 \%$ with 212/216 trials found in agreement.

Plan of Analysis A mixed methods experimental-descriptive design was used to examine the effects of three experimental listening conditions - noise at $45 \mathrm{~dB}$, noise at $65 \mathrm{~dB}$, and artificially attenuated noise (i.e., silence) as the control - on the accuracy of novel vocabulary learning for collegeaged students. Data were collected at pre-test and post-test time points using time and listening condition as independent variables. Data were analyzed using logit mixed effects models fit with the lme4 package for R (Bates, 2007) to estimate the log odds of responding accurately as a function of the within-subject independent variables as well as random effects of participants and target words. As previously mentioned, it was hypothesized that louder background noise (i.e., multi-talker babble) would have the most detrimental effect on word learning 


\section{RESULTS}

Data from all 29 participants were included in the analyses. To address the aim of the study, which was to investigate the impact of multi-talker background noise on the contextualized word learning of adults, two models were fit to analyze the data. The first model compared pre-test and post-test accuracy collapsed across listening conditions to test for an overall learning effect from pre-test to post-test. Results showed a significant learning effect in which participants performed significantly better at post-test than pre-test after accounting for random effects of participant and target word $(\beta=2.35, z=3.86, p<0.001)$. On average, participants improved from $10.54 \%$ accuracy at pre-test to $26.82 \%$ accuracy at post-test, and observation of the performance accuracy data for individual participants showed that 28 of 29 participants demonstrated improvement from pre-test to post-test. See Table 3 below.

Table 3. Means (M) and standard deviations (SD) for participants' percent accuracy at pre-test, post-test overall, and post-test as a function of listening condition.

\begin{tabular}{|c|c|c|}
\hline Condition & $\begin{array}{c}\text { Pre-Test } \\
M(S D)\end{array}$ & $\begin{array}{c}\text { Post-Test } \\
M(S D)\end{array}$ \\
\hline Overall & $10.54 \%(6.74 \%)$ & $26.82 \%(15.23 \%)$ \\
\hline after Quiet & -- & $25.86 \%(22.14 \%)$ \\
\hline after 45dB noise & -- & $23.56 \%(23.78 \%)$ \\
\hline after 65 dB noise & -- & $31.03 \%(23.46 \%)$ \\
\hline
\end{tabular}

Random effects of participants and target words were included in the model to determine if accounting for the natural variance in individual participant performance and/or in stimuli significantly improved the model fit. While including both by-subject and by-word differences did improve the fit and therefore were included in the final model, the by-subject variance contributed marginally, which is consistent with the relatively small subject variance reported in Table 3. In contrast, the by-word variance contributed significantly to the model fit, with a large variance and a very strong negative correlation between performance on a word at pre-test and performance at post-test (Pearson's $r=-0.086$; see Table 4). Random intercepts and slopes for each target word are listed in Table 5 depicting the very strong negative correlation: words that were less well-known during the pre-test (i.e. had a lower average 
accuracy) were more likely to show larger learning effects than words that were more well-known during the pre-test.

Table 4. Summary of logit mixed-effects model of accuracy from pre-test to post-test (model 1)

\begin{tabular}{|l|c|c|c|c|}
\hline Random effects & & Variance & $\boldsymbol{S D}$ & Pearson $\boldsymbol{r}$ \\
\hline Participant & Intercept & 0.46 & 0.68 & \\
\hline Word & Intercept & 4.78 & 2.19 & -0.86 \\
\hline & Post-Test & 2.31 & 1.52 & $\boldsymbol{p}$ \\
\hline Fixed effects & & & $\boldsymbol{Z}$ & $<0.001$ \\
\hline Intercept & $\boldsymbol{\beta}$ & $\boldsymbol{S E}$ & -5.15 & $<0.001$ \\
\hline Post-Test & -3.69 & .61 & 3.87 & \\
\hline
\end{tabular}

Table 5. Random intercepts and slopes for target words

\begin{tabular}{|c|c|c|c|}
\hline $\begin{array}{c}\text { Passage } \\
\text { Pair }\end{array}$ & Target Word & Intercept & Post-Test \\
\hline 2 & ABERRATION & -2.21 & 0.76 \\
\hline 3 & IMPETUS & -2.21 & 0.76 \\
\hline 2 & ONEROUS & -1.53 & 0.71 \\
\hline 3 & PRETENSIONS & -1.53 & 0.71 \\
\hline 3 & SOPHISTRY & -1.29 & 0.72 \\
\hline 2 & EQUIVOCAL & -1.10 & 0.74 \\
\hline 2 & SAGACITY & -1.10 & 0.74 \\
\hline 3 & ARBITER & -0.28 & 1.04 \\
\hline 1 & POTENTATES & -0.21 & 1.09 \\
\hline 1 & COUNTENANCE & 0.43 & 0.25 \\
\hline 3 & ACQUIESCE & 0.46 & -1.22 \\
\hline 3 & DENOTATIVE & 0.68 & -0.84 \\
\hline 1 & CONSTERNATION & 0.84 & -0.52 \\
\hline 2 & AGGRANDIZE & 1.82 & -1.69 \\
\hline 1 & VOCIFEROUS & 2.25 & -2.24 \\
\hline 1 & DISSUADED & 3.10 & -1.60 \\
\hline 1 & PALATABLE & 3.16 & -1.04 \\
\hline 2 & IDYLLIC & 3.56 & -1.66 \\
\hline
\end{tabular}

After confirming with the first model that learning occurred from pre-test to post-test, the primary objective of the study to examine the effect of background noise in word learning was analyzed. The second logit mixed effects model assessed whether there were differences in post-test performance after 
training in relative quiet or the two listening conditions. Dummy variables were created as fixed effects to make three direct comparisons: (1) pre-test scores (taken in quiet) and post-test scores after training in the $65 \mathrm{~dB}$ listening condition, (2) post-test scores after training in quiet compared to the $45 \mathrm{~dB}$ listening condition, and (3) post-test scores after training in $45 \mathrm{~dB}$ compared to the $65 \mathrm{~dB}$ condition.

Results showed no significant effect of noise on the post-test accuracy outcomes, as indicated by no significant effect of the comparison between target words trained in quiet versus in $45 \mathrm{~dB}$ background noise $(\beta=0.10, z=0.33, p=0.74)$ nor a significant effect comparing accuracy at post-test on words trained in $45 \mathrm{~dB}$ background noise to those trained in $65 \mathrm{~dB}$ background noise $(\beta=-0.32, z=-1.11, p=$ 0.27; See Table 6). Random effects of subject and target word contributed a similar degree to the model as they did in the first model - i.e. the by-word effect was substantial while the by-subject effect was marginal based on variances displayed below and a strong negative correlation reported.

Table 6. Summary of logit mixed-effects model of accuracy across listening conditions (model 2)

\begin{tabular}{|l|c|c|c|c|}
\hline Random effects & & Variance & $\boldsymbol{S D}$ & Pearson $\boldsymbol{r}$ \\
\hline Participant & Intercept & 0.46 & 0.68 & \\
\hline Word & Intercept & 4.78 & 2.19 & \\
\hline & Post-Test & 2.32 & 1.52 & -0.86 \\
\hline & & & & \\
\hline Fixed effects & $\boldsymbol{\beta}$ & $\boldsymbol{S E}$ & $\boldsymbol{Z}$ & $\boldsymbol{p}$ \\
\hline Intercept & -3.69 & 0.72 & -5.15 & $<0.001$ \\
\hline Pre-test - Post-test 65 dB & 2.53 & 0.63 & 4.02 & $<0.001$ \\
\hline Post-Test (Quiet - 45 dB) & 0.10 & 0.29 & 0.33 & 0.74 \\
\hline Post-Test (45 dB -65 dB) & -0.32 & 0.28 & -1.11 & 0.27 \\
\hline
\end{tabular}

The summary of the second mixed model revealed no significant differences in accuracy among the listening conditions, yet the post-test scores in all three conditions were generally low $(\leq 31 \%)$ leaving open the question of whether the participants did not put effort into the task or the post-test was too difficult and muted any potential differences between the listening conditions. Thus, a secondary post hoc analysis on the accuracy data of the matching task immediately following each training set was performed. As part of the word learning training, participants completed the matching task at the end of 
each training set. In contrast to the comprehensive open-ended post-test using all 18 target words, the matching task was presumably an easier task given that (1) it was completed immediately following the training for each subset of words, (2) it included only the six target words in that set, and (3) it required multiple-choice responses. Another difference between the matching task and final post-test is that the matching task was completed in the respective noise condition during training whereas the post-test was completed in quiet. A one-way repeated measures analysis of variance (ANOVA) was completed to assess any potential effect of noise as participants completed the matching task. It was observed that participants' average accuracy decreased as noise level increased $\left(M(S D)_{\text {quiet }}=55.1 \%(27.1 \%), M(S D)_{45}\right.$ $d B$ noise $=51.1 \%(26.3 \%), M(S D)_{65} d B$ noise $\left.=40.2 \%(31.0 \%)\right)$, although the standard deviations were large and the ANOVA results were not statistically significant $(F(2,56)=2.01, p=0.14)$. The average accuracy across listening conditions was substantially larger for the matching task $(M(S D)=48.8 \%$ $(28.4 \%))$ compared to the average accuracy across listening conditions for the post-test $(M(S D)=26.8 \%$ $(15.2 \%))$, suggesting that the post-test may have been too difficult though the participants seem to put in at least modest effort during the training. The pattern of these results also may suggest an impact of noise on word learning performance (i.e., accuracy is worse in louder conditions) when the task is not too difficult, though this claim is tenuous given the lack of statistical significance in the post hoc ANOVA.

\section{DISCUSSION}

When learning in the school setting or reading and studying independently, many students find themselves in noisy environments. Despite intentional redundancy in the speech signal, conversation and classroom content is novel and, due to its instantaneous nature, can be missed in poor acoustical conditions. Accurate perception of the acoustic signal is essential to effective listening and learning for students of all ages and hearing abilities. While context may often facilitate new vocabulary learning in noise, any disruptions to attention may affect memory and eventual language learning outcomes. This study aimed to investigate the impact of multi-talker babble background noise that differed in intensity on 
the contextualized vocabulary learning of adults as they silently read short passages. Additional facilitative context was provided for 18 target words in the form of vocabulary practice activities. Better understanding the impact of noise on learning is foundational to future work that can optimize technology, the acoustic environment, and inclusive teaching techniques to create a positive learning environment in the mainstream classroom for children with and without hearing impairment.

The primary aim of the study was to investigate the effect of background noise on adults' word learning ability when reading narrative passages. Because this was a novel word learning task, the first analysis tested for overall learning from pre-test to post-test, followed by an analysis to test the primary question regarding performance accuracy at post-test as a function of listening condition. Results from the mixed-modeling analyses showed a clear learning effect across subjects and words from pre-test to posttest demonstrated by significantly improved accuracy on the same 18 target words in spite of the "noisy" training conditions for two-thirds of the words. While it was hypothesized that the louder multi-talker babble would have the most detrimental effect on vocabulary learning, the second model examining accuracy data between the listening conditions and quiet found no statistically significant differences in participants' performance. An unexpected result was the relatively high accuracy on the words that had been trained in $65 \mathrm{~dB}$ of background noise as compared to the other two listening conditions. However, when considering the input and output demands of the task, the findings are consistent with much of the current literature.

Previous work testing noise effects with reading/writing tasks (i.e., tasks with no auditory input or spoken output), similar to the input and output demands of the current study, have shown that linguistic tasks that do not have an auditory or spoken component may not be significantly affected by noise. For example, Halin and colleagues (2014) examined the basic idea of a trade-off between the level of concentration and distractibility to test whether the manipulation of task difficulty can shield against distraction. Participants read, either in quiet or with a speech noise background, texts that were displayed 
either in an easy-to-read or a hard-to-read font. Background speech impacted prose recall, but only when the text was displayed in the easy-to-read font. Recall improved in the background speech condition for hard-to-read than for easy-to-read texts. Moreover, individual differences in working memory capacity were related to the magnitude of disruption, but only in the easy-to-read condition. This suggests that increased task difficulty can facilitate one's selective attention in noisy work environments by promoting focused task engagement. This also supports the findings of the current study in that participants may have performed better in the louder listening condition due to enhanced focus.

In contrast, many previous studies that found effects of noise on learning included speech recognition or expressive/spoken language tasks. For example, Riley and McGregor (2012) trained words in broadband white noise and examined expressive word learning and production in response to more or less perceptible signals (varied SNR). With an expectation of spoken output, an impact was found on the articulation and clarity of the spoken responses trained in noise. Similarly, Harmon et al. (2021) investigated how different types of background noise that differ in their level of linguistic content affected speech fluency and language production for young adult speakers when performing a monologue discourse task. Measures related to speech acoustics, speech fluency, and language production were analyzed and compared across conditions. All noise conditions resulted in some change to spoken language compared with the silent baseline. Effects on speech fluency showed decreased pausing and increased disfluencies. Several background noise conditions also seemed to interfere with spoken language production. Effects of noise are also present in speech perception tasks using words and sentences (e.g., Bradlow et al., 2003; Jamieson et al., 2004; Klatte, Hellbrück, et al., 2010; Klatte, Lachmann, et al., 2010; Massaro \& Light, 2004; Stelmachowicz et al., 2000, 2004)

Thus, it can be concluded that tasks with auditory input or spoken language output requirements are more susceptible to speech background noise than language tasks without such requirements. The results of the current study, in which there were no significant effects of noise with a word learning task 
that required participants to read passages and type definitions of the words they learned, add to this body of work.

Another consideration to potentially explain the finding that there were no significant differences in post-test scores between the listening conditions is the idea of habituation. Perhaps people are so accustomed to background noise in their learning environments that minimal noise is not detrimental to learning and could even enhance focus to allow for learning in spite of distractions. Also, since this was a reading task rather than a true speech recognition task, the louder background noise could have increased participant focus. Consistent with the idea that humans adapt to noisy environments that they routinely encounter during daily activities is the finding that the highest percentage of accuracy was noted on words that were trained in $65 \mathrm{~dB}$, the loudest condition (though again, this result was not statistically significant). Work by Khalighinejad, Herrero, Mehta, and Mesgarani (2019) directly measured neural activity in the auditory cortex of six human subjects as they listened to speech with abruptly changing background noises. Rapid and selective suppression of acoustic features of the noise was noted in the neural responses, resulting in enhanced representation and perception of speech acoustic features. The degree of adaptation to different background noises varied across neural sites and was predictable from the tuning properties and speech specificity of the sites. Moreover, adaptation to background noise was unaffected by the attentional focus of the listener. The authors concluded that the convergence of these neural and perceptual effects reveals the ability of a listener to filter out irrelevant sound sources in a changing acoustic scene. This study illustrates the notion that humans adapt, somewhat subconsciously, to certain distractions to successfully navigate daily environments. In other words, our listening capabilities evolve to prioritize attention to important, meaningful sounds such as discernible speech and we can acclimate to background noise. 


\section{Participant Effort}

Although this study showed an overall learning effect from pre-test to post-test, the average overall post-test accuracy was still quite low (26.82\%). Several explanations could account for these results. First, attention and effort are necessary components to learning new information such as vocabulary (Gupta, 2005; Nematzadeh et al., 2012; Silvia et al., 2010). Therefore, one explanation for these low scores may be due to participants' lack of effort. According to Silvia, McCord, and Gendolla (2010), Dr. Jack Brehm's motivational intensity theory predicts that "the intensity of motivation is only as high as necessary, so people will try harder for difficult tasks than for easy tasks" (p. 364). In other words, people will only put forth as much effort as necessary to achieve a goal. Brehm proposes that effort is jointly determined by two variables: the difficulty of the goal and the perceived importance of the goal. Regarding the difficulty of the goals of the current study, participants were made aware that the words would be challenging and were encouraged to guess if they were unsure. It was expected that the task would be difficult, yet not overly so that participants would give up and be unable to complete the tasks or the training sets. Considering Brehm's theory, individual perception of goal difficulty and necessary motivation to complete something is somewhat subjective and outside of research control. Participants were informed of the general purpose of the research and expectations of them. However, the perceived importance of that goal could vary from participant to participant and thus affect individual effort and outcomes.

A post hoc analysis attempted to evaluate effort by examining how participants performed on a simpler matching task that was a part of each training set. The matching task is arguably an easier task because it requires recognition (opposed to recall in the post-test) with only six words (compared to all 18 words in the post-test) and is completed immediately after each training set (rather than after a delay, such as the post-test). The premise was that, if participants were making at least some effort during the experiment to learn the words, they should have higher performance on a relatively simple task that was part of the training. The findings did indeed show that average performance was substantially higher for 
the matching task (48.8\% overall accuracy, range $40.2 \%-55.1 \%$ depending on listening condition) compared to the post-test scores. Thus, low scores on the post-test cannot be explained entirely from lack of effort; at least a modest effort seemed to be involved with completing the training.

Although the matching task performance offers evidence that the participants are making some effort during training, their performance on this relatively simple matching task, albeit higher than the post-test scores, is only around 50\% accuracy, so it is possible that effort could be improved. Participants' effort was encouraged in the instructions at the beginning of the experiment as well as with reminders at each training set to "try your best to learn the new words." Participants were also informed of the broad intent of the research and were encouraged to give a best guess to each item even though the words were intentionally hard and probably unfamiliar to them. Upon reflection of these scores, several things could be done in future work to incentivize effort. For example, providing more focused instruction specifically addressing effort might improve their participation. Additionally, more feedback throughout the training sets could improve effort by allowing participants to gauge their own performance and allow the possibility for real-time adjustments to effort and accuracy. Another way to increase effort could be to provide different compensation. While extra credit was offered to each participant upon completion of the

study, future work could include a reward system based on effort or performance. In addition to providing ways to improve effort, it also could be beneficial in future work to assess participants' effort level throughout training, for example by including a qualitative component of the training and asking participants to rate their effort.

\section{Task and training set design}

Another reason the post-test scores may have been low could be because the post-test task itself was too difficult or the training could be bolstered to facilitate learning. Given the matching task results were generally higher than the post-test scores, it is possible that the design of the task may have contributed to performance. The matching task only required recognition of the target words using 
synonyms that were included in the engagement activities, whereas recall for the post-test (as well as pretest) required the participants to generate their own response. A recall task requires more effort and is more linguistically demanding than a recognition task. Additionally, the training activities did not include recall so the participants did not have an opportunity to practice generating definitions once they learned the meaning of the words but before the post-test.

This leads to another possibility for low post-test scores: perhaps more could have been done to facilitate the learning of the words during the training. The target words were introduced in short, narrative passages to provide a context to facilitate learning. However, because the stories were taken from a standardized assessment, perhaps they were inaccessible, and participants did not understand or relate well with the stories. While comprehension questions were administered following each story to encourage participants to read the stories and not just skip to the engagement activities, responses to the comprehension questions were not scored. Future analyses could examine participant performance on the comprehension questions to evaluate participants' understanding of the story content to see if that could have been a barrier to learning the new words. If the context of the stories was a hindrance, then it would make sense that overall learning of the target words would be compromised as well. Perhaps more exposures and more salient practice with the vocabulary including more meaningful context would have facilitated learning. Future work could vary the type and genre of story (fiction vs. non-fiction; relatable vs. novel) to see the extent to which story context or type impacts vocabulary learning. Lastly, the training included only receptive tasks; perhaps more expressive opportunities to use the target words or including more interactive vocabulary activities similar to Adlof's (2019) DictionarySquared.com program would have improved the training and better prepared participants for success on the post-test. The DictionarySquared.com program is individually tailored to student knowledge and designed to increase academic vocabulary and reading comprehension. In addition to incorporating relevant videos and 
pictures, some of the interactive activities include audio practice with target words, writing definitions, generating sentences, matching synonyms, filling in the blanks, and creating memes.

\section{Random effects of target words}

A final finding of note is the random effects of the target word stimuli. It was observed that words that were most unknown at pre-test (i.e. had the lowest pre-test accuracy) in general tended to show the most learning at post-test (see Table 5). This result may be explained simply by the idea that there is naturally more room for improvement in words with the lowest overall accuracy. This pattern of change from pre-test to post-test also could be due to a priori knowledge of participants. While the words were intentionally selected to be unknown, the pre-test was scored in a binary all-or-nothing fashion and did not account for familiarity of the word. Furthermore, some words may be easier to learn because of individual subjects' relevant experience and exposure to the target words as well as the lexical characteristics of the words themselves. There is evidence to show that lexical characteristics such as imageability, concreteness, and grammatical function could impact performance on linguistic tasks (Beck et al., 2013; Justice et al., 2005; Nippold \& Haq, 1996). Future work could directly test these variables related to participant and stimuli characteristics.

\section{Limitations and future considerations}

As noted in the previous sections, future studies involving word learning in background noise could evaluate the components of the training design including task difficulty and performance expectations such as receptive versus expressive and written versus spoken output to better understand the impact of noise in learning. Additionally, although counterbalancing was used for the study to control for potential confounds of task order, not all aspects of the task order were completely counterbalanced. Thus, any impact of this confound was only minimized rather than eliminated. While there may not be enough power to include task order variables as fixed effects in the current models, future work could address this. 
The work reported here supports the idea that many factors such as attention and focus are critical to the learning process. If background noise has the potential to affect learning in typically hearing individuals, what would the impact be in those with hearing loss who already have some form of physiological disruption to auditory input? As children with hearing impairment are often listening and learning alongside typically hearing peers, it is important to understand how they learn and the different ways in which varied noise impacts their learning. Future work could compare performance between children with hearing loss and their typically hearing peers to help identify which tasks are impacted by noise and what modifications to daily learning environments can facilitate effective learning for those with hearing loss. 
APPENDIX A. GORT-5 Selected Reading Passages (target words are emboldened)

\section{Form A; Passage 12}

The Queen was one of the potentates who attempted things that no reputable sovereign would have dared venture on and achieved those in which none but the most intrepid could have succeeded. she consulted with very few upon any action of import, nor communicated any enterprise with more than those who were to have principal parts in the execution of it, nor sooner than was absolutely necessary. What she once resolved she would not be dissuaded from or endure any contradiction of her authority, but exhorted submission, even from those who were not willing to yield it except at the guillotine. Yet she seemed much afflicted by the demise of her councilor, Claypole, who conferred with her in his last hours. Although no one could catch the particulars, it was concluded that he repented of his pains to implement the Queen's wishes and presented her worst actions to her for consideration. Although she never made the least show of remorse for any of her deeds, her countenance was much altered after this encounter.

Word Count: 173

Reading Ease: 42.2

Grade Level: 14.5

\section{Form A; Passage 13}

Certainly Harriet had lately been cognizant of Mr. Weston's unnecessary chivalry, but she had construed it as an aberration of judgement or taste, as proof among others that he had not always moved in the best circles, that with all his assiduous concern for her, the accoutrements of true gentility were wanting. But until now she had never surmised it to be anything; his manner must have been equivocal, or she could not have been so beguiled. Contrary to her wont, she found these protestations importunate and his proposal a breach of propriety. Of course, he wanted to marry well, but to have the temerity to hope for anything but amicable tolerance from one so manifestly his superior proved that he only wanted to 
aggrandize himself. So, she need not trouble herself to feel clemency. He was proving himself assuming, conceited, very full of his own claims, and with little heed for the feelings of others.

Word Count: 156

Reading Ease: 48.8

Grade Level: 12.0

\section{Form A; Passage 14}

While industry's magnates saddled themselves with the onerous responsibility of ameliorating the wilderness on the town's periphery with decorous replicas of Italian villas, it must not be inferred that the requisites of the disenfranchised class were in any way slighted. Gargantuan housing developments sprang up on which, by the exercise of remarkable sagacity and imagination, quite a fantastic number of families were accommodated. (Great was the anxiety lest the workers should feel too estranged from the sight or sound of the mills that were the scene of their idyllic labors.) In order that the inhabitants might have the privilege of ruminating, almost incessantly, on the epitome of human technological triumph, many of the edifices were thoughtfully constructed alongside the new thoroughfare or even, if there was a viaduct handy, underneath it.

Word Count: 131

Reading Ease: 12.8

Grade Level: 19.6

\section{Form A; Passage 15}

In the spacious expanse of Western territory, consequently, we perceive an abundant theater for hostile pretensions, without any arbitrator or common judge to interpose between the contending factions. To deduce from the past to the future, we shall have excellent ground to apprehend that the sword would occasionally be appealed to as the arbiter of their disagreements. The circumstances of the dissention 
between Connecticut and Pennsylvania, respecting the terrain at Wyoming, admonish us not to be sanguine in expecting a straightforward accommodation of such differences. The Articles of Confederation obliged the parties to submit the matter to the resolution of a federal judiciary. The submission was completed, and the court decided, after careful contemplation and deliberation, in favor of Pennsylvania. But Connecticut rendered fervent indications of dissatisfaction with that determination; nor did she appear to be entirely resigned to it, until, by negotiation and management, something like an equivalent was found for the grievance she supposed herself to have sustained. Nothing here said is intended to convey the slightest censure of the demeanor of that State. She no doubt sincerely considered herself to have been victimized by the pronouncement; and States, like individuals acquiesce with enormous reluctance in determinations to their disadvantage.

Word Count: 202

Reading Ease: 20.4

Grade Level: 16.7

\section{$\underline{\text { Form B; Passage } 13}$}

We accept the terms movie, film, and cinema as synonymous, assuming that their usage simply connotes the critic's level of pretentiousness. The term movie, however, usually bespeaks an entertaining piece based on a commercial impetus and indulging the crass tastes of a mass audience. The terms film and cinema, on the other hand, suggest creations that posit a more intellectually and aesthetically elite audience. There are denotative differences as well. The three terms reflect the fact that a motion picture is a spatial photographic medium (film), a process with a temporal dimension (cinema), and a stylized genre (movie). The point of distinguishing among these terms is not an exercise in sophistry or an attempt to force audiences into the alien habit of differentiating among terms they accept as synonyms. Theorists, however, should be more discriminating, for using the terms synonymously has caused genuine 
theoretical confusion, and more precise definitions can reveal precisely what question the theorist intends to answer.

Word count: 159

Reading Ease: 23.1

Grade Level: 15.7

\section{Form B; Passage 14}

Public consternation over the delineation of violence and crime in the media oscillates, usually peaking in response to the emergence of a new popular genre grounded in violence and crime. On the heels of this vociferous concern, scientific studies spring up, purporting to show a definite causal connection between violence and crime in the media and criminal behavior. Moral pressure groups soon issue censures that culminate in legislative investigations. Then the medium under fire announces with great éclat a program of self-regulation, which results at least temporarily in a reduction in the level of violent content or in a more palatable mode of the presentation of violent themes. Finally, another spate of scientific inquiries invalidates the causal claims of the preceding studies and suggests that the correlation between media violence and violent behavior is more tangential than was assumed and cannot be characterized in terms of a simple cause --- effect equation. Thus, the issue is defused until it is again broached in relation to a new generic development.

Word count: 168

Reading Ease: 17.7

Grade Level: 17.8 


\section{APPENDIX B. The Flesch Reading Ease Score and Flesch-Kincaid Grade Level}

The Flesch Reading Ease Score was first used in 1948 to show how readable a text is. The score lets you know the approximate educational level a person will need to be able to read a particular text easily. How comprehensible a document is will be indicated on the Flesch Reading Ease Score by a number between 0 and 100. The higher the score, the more readable the text. These scores are used by policy writers, research communicators, and digital marketers in order to find how easily a target audience will be able to understand and engage with a particular text.

\begin{tabular}{|c|c|}
\hline Score & Estimated Reading Grade Level \\
\hline 90 to 100 & 5 th grade \\
\hline 80 to 90 & 6 th grade \\
\hline 70 to 80 & 7th grade \\
\hline 60 to 70 & 8th and 9th grade \\
\hline 50 to 60 & 10th to 12 th grade (high school) \\
\hline 30 to 50 & College \\
\hline 0 to 30 & College graduate \\
\hline
\end{tabular}

Note. Figure taken directly from https://goodcalculators.com/flesch-kincaid-calculator/

The Flesch Reading Ease score is arrived at by using this equation:

Flesch Reading Ease Score $=206.835-1.015 \times($ Total Words $/$ Total

Sentences $)-84.6 \times($ Total Syllables / Total Words $)$

The Flesch-Kincaid Grade Level shows what educational level a person will need to understand a particular text. The scores created by the Flesch-Kincaid Grade Level align with the US educational grade levels at which readers are suggested to be in order to comprehend a particular text. For example, if the text has a Flesch-Kincaid Grade Level of 9, it is suggested that the reader would have had to have undergone around nine years of education (i.e., reached around 9th grade) to understand the reading 
passage. The Flesch-Kincaid Grade Level is assessed by examining how many words, sentences, and syllables a document contains, employing the equation below:

Flesch-Kincaid Grade Level $=0.39 \times($ Total Words $/$ Total Sentences $)+11.8 \times($ Total Syllables $/$ Total Words) -15.59

https://goodcalculators.com/flesch-kincaid-calculator/ 
APPENDIX C. Brief History Questionnaire

\begin{tabular}{|c|l|l|}
\hline 1 & Date of birth & 1. \\
\hline 2 & Current age/grade & 2. \\
\hline 3 & Sex (M/F) & 3. \\
\hline 4 & What is your primary/native language? & 4. \\
\hline 5 & What language(s) do you speak regularly? & 5. \\
\hline 6 & Any known general/non-language learning difficulties? & 6. \\
\hline 7 & Have you been diagnosed with ADHD? & 7. \\
\hline 7 a & \multicolumn{1}{|c|}{ If so, is it managed with medication? } & $7 \mathrm{a}$. \\
\hline $7 \mathrm{~b}$ & & $7 \mathrm{~b}$. \\
\hline 8 & Any history of hearing difficulties? Treatment? & 8. \\
\hline 9 & Any history of speech/language difficulties? Treatment? & 9. \\
\hline 10 & Any history of cognitive difficulties? Treatment? & 10. \\
\hline 11 & Any known current hearing difficulties? & 11. \\
\hline 12 & Any known current speech/language difficulties? & 12. \\
\hline 13 & Any known current cognitive deficits? & 13. \\
\hline 14 & Any known vision difficulties (not correctable with & 14. \\
\hline 15 & Alasses)? & 15. \\
\hline
\end{tabular}

Notes: 


\section{REFERENCES}

Adlof, S. M. (2019). Prologue to the forum: Vocabulary across the school grades. Language, Speech, and Hearing Services in Schools, 50(4), 461-465. https://doi.org/10.1044/2019_LSHSS-19-00007

Adlof, S. M., Baron, L., Scoggins, J., Kapelner, A., McKeown, M., Perfetti, C. A., Miller, M., Soterwood, J., \& Petscher, Y. (2019). Accelerating adolescent vocabulary growth: Development of an individualized, web-based, vocabulary instruction program. Language, Speech, and Hearing Services in Schools, 50(4), 579-595. https://doi.org/10.1044/2019_LSHSS-VOIA-18-0143

Anwyl-Irvine, A. L., Massonnié, J., Flitton, A., Kirkham, N. Z., \& Evershed, J. K. (2019). Gorilla in our midst: An online behavioural experimental builder. Behavior Research Methods. www.gorilla.sc; https://doi.org/10.3758/s13428-019-01237-x

Baddeley, A. D. (2003). Working memory and language: An overview. Journal of Communication Disorders, 36(3), 189-208.

Baddeley, A. D., Gathercole, S. E., \& Papagno, C. (1998). The phonological loop as a language learning device. Psychological Review, 105(1), 158-173.

Bates, D. (2007). lme4: An R package for fitting and analyzing linear, non-linear, and generalized linear mixed models [Software Application].

Beck, I., McKeown, M., \& Kucan, L. (2013). Bringing Words to Life: Robust Vocabulary Instruction (2nd ed.). The Guilford Press.

Berg, F. (1987). Facilitating Classroom Listening: A handbook for teachers of normal hearing and hard of hearing students. Pro-Ed.

Berg, F. (1993). Acoustics and Sound Systems in Schools. Singular.

Bradlow, A., Kraus, N., \& Hayes, E. (2003). Speaking clearly for children with learning disabilities. Journal of Speech, Language, and Hearing Research, 46(1), 80-97. https://doi.org/10.1044/10924388(2003/007)

Coyne, M. D., Simmons, D. C., Kame'enui, E. J., \& Stoolmiller, M. (2004). Teaching vocabulary during shared storybook readings: An examination of differential effects. Exceptionality, 12(3), 145-162. https://doi.org/10.1207/s15327035ex1203_3

Crandell, C. C., \& Smaldino, J. J. (2000). Classroom acoustics for children with normal hearing and with hearing impairment. Language, Speech, and Hearing Services in Schools, 31(4), 362-370.

https://doi.org/10.1044/0161-1461.3104.362

Dockrell, J. E., \& Shield, B. M. (2006). Acoustical barriers in classrooms: The impact of noise on performance in the classroom. British Educational Research Journal, 32(3), 509-525. JSTOR.

Ehri, L. C. (2014). Orthographic mapping in the acquisition of sight word reading, spelling memory, and vocabulary learning. Scientific Studies of Reading, 18(1), 5-21.

https://doi.org/10.1080/10888438.2013.819356 
Elliot, L. (1979). Performance of children aged 9 to 17 years on a test of speech intelligibility in noise using sentence material with controlled word predictability. Journal of the Acoustical Society of America, 66.

Fallon, M., Trehub, S. E., \& Schneider, B. A. (2000). Children's perception of speech in multitalker babble. The Journal of the Acoustical Society of America, 108(6), 3023-3029. https://doi.org/10.1121/1.1323233

Finitzo-Hieber, T., \& Tillman, T. W. (1978). Room acoustics effects on monosyllabic word discrimination ability for normal and hearing-impaired children. Journal of Speech and Hearing Research, 21(3), 440-458. https://doi.org/10.1044/jshr.2103.440

Flack, Z. M., Field, A. P., \& Horst, J. S. (2018). The effects of shared storybook reading on word learning: A meta-analysis. Developmental Psychology, 54(7), 1334-1346. https://doi.org/10.1037/dev0000512

Gaskell, M. G., \& Dumay, N. (2003). Lexical competition and the acquisition of novel words. Cognition, 89(2), 105-132.

Gathercole, S. E., \& Baddeley, A. (1989). Evaluation of the role of phonological STM in the development of vocabulary in children: A longitudinal study. Journal of Memory and Language, 28, 200-213.

Gathercole, S. E., Willis, C. S., Emslie, H., \& Baddeley, A. D. (1992). Phonological memory and vocabulary development during the early school years: A longitudinal study. Development Psychology, 28(5), 887-898.

Gupta, P. (2003). Examining the relationship between word learning, nonword repetition, and immediate serial recall in adults. The Quarterly Journal of Experimental Psychology, 56A(7), 1213-1236.

Gupta, P. (2005). What's in a word? A functional analysis of word learning. Language Learning and Education, 4-8.

Halin, N., Marsh, J. E., Hellman, A., Hellström, I., \& Sörqvist, P. (2014). A shield against distraction. Journal of Applied Research in Memory and Cognition, 3(1), 31-36. https://doi.org/10.1016/j.jarmac.2014.01.003

Han, M. K., Storkel, H., \& Cox, C. (2012). The effect of noise on adults' word learning. 1.

Han, M. K., Storkel, H., Lee, J., \& Cox, C. (2016). The effects of phonotactic probability and neighborhood density on adults' word learning in noisy conditions. American Journal of SpeechLanguage Pathology, 25(4), 547. https://doi.org/10.1044/2016_AJSLP-14-0165

Harmon, T. G., Dromey, C., Nelson, B., \& Chapman, K. (2021). Effects of Background Noise on Speech and Language in Young Adults. Journal of Speech, Language, and Hearing Research, 64(4), 1104-1116. https://doi.org/10.1044/2020_JSLHR-20-00376

Hoen, M., Meunier, F., Grataloup, C.-L., Pellegrino, F., Grimault, N., Perrin, F., Perrot, X., \& Collet, L. (2007). Phonetic and lexical interferences in informational masking during speech-in-speech comprehension. Speech Communication, 49(12), 905-916. https://doi.org/10.1016/j.specom.2007.05.008 
Hoover, J., Storkel, H., \& Hogan, T. (2010). A cross-sectional comparison of the effects of phonotactic probability and neighborhood density on word learning by preschool children.

https://core.ac.uk/reader/191530340

Jamieson, D. G., Kranjc, G., Yu, K., \& Hodgetts, W. E. (2004). Speech intelligibility of young schoolaged children in the presence of real-life classroom noise. Journal of the American Academy of Audiology, 15(7), 508-517. https://doi.org/10.3766/jaaa.15.7.5

Justice, L. M. (2002). Word exposure conditions and preschoolers' novel word learning during shared storybook reading. Reading Psychology, 23(2), 87-106. https://doi.org/10.1080/027027102760351016

Justice, L. M., Meier, J., \& Walpole, S. (2005). Learning new words from storybooks: An efficacy study with at-risk kindergartners. Language Speech and Hearing Services in Schools, 36(1), 17. https://doi.org/10.1044/0161-1461(2005/003)

Kenyon, E. L., Leidenheim, S. E., \& Zwillenberg, S. (1998). Speech discrimination in the sensorineural hearing loss patient: How is it affected by background noise? Military Medicine, 163(9), 647-650. https://doi.org/10.1093/milmed/163.9.647

Khalighinejad, B., Herrero, J. L., Mehta, A. D., \& Mesgarani, N. (2019). Adaptation of the human auditory cortex to changing background noise. Nature Communications, 10(1), 2509.

https://doi.org/10.1038/s41467-019-10611-4

Klatte, M., Bergstroem, K., \& Lachmann, T. (2013). Does noise affect learning? A short review on noise effects on cognitive performance in children. Frontiers in Psychology, 4.

https://doi.org/10.3389/fpsyg.2013.00578

Klatte, M., Hellbrück, J., Seidel, J., \& Leistner, P. (2010). Effects of classroom acoustics on performance and well-being in elementary school children: A field study. Environment and Behavior, 42(5), 659-692. https://doi.org/10.1177/0013916509336813

Klatte, M., Lachmann, T., \& Meis, M. (2010). Effects of noise and reverberation on speech perception and listening comprehension of children and adults in a classroom-like setting. Noise and Health, 12(49), 270. https://doi.org/10.4103/1463-1741.70506

Lidestam, B., Holgersson, J., \& Moradi, S. (2014). Comparison of informational vs. Energetic masking effects on speechreading performance. Frontiers in Psychology, 5. https://doi.org/10.3389/fpsyg.2014.00639

MacGregor, K., Marshall, B., Julian, S., \& Oleson, J. (2019). Learning while playing: A randomized trial of serious games as a tool for word mastery. Language, Speech, and Hearing Services in Schools, 50.

Marulis, L. M., \& Neuman, S. B. (2013). How vocabulary interventions affect young children at risk: A meta-analytic review. Journal of Research on Educational Effectiveness, 6(3), 223-262.

https://doi.org/10.1080/19345747.2012.755591

Massaro, D. W., \& Light, J. (2004). Using visible speech to train perception and production of speech for individuals with hearing loss. Journal of Speech, Language, and Hearing Research, 47(2), 304-320. https://doi.org/10.1044/1092-4388(2004/025) 
Maxwell, L. E., \& Evans, G. W. (2000). The effects of noise on preschool children's pre-reading skills. Journal of Environmental Psychology, 20(1), 91-97. https://doi.org/10.1006/jevp.1999.0144

McDiarmid, E. W., \& Tatum, G. R. (1938). Library noise. The Library Quarterly: Information, Community, Policy, 8(2), 200-209. JSTOR.

McSporran, E. (1997). Towards better listening and learning in the classroom. Educational Review, 49(1), 13. https://doi.org/10.1080/0013191970490102

Miller, G., Heise, G., \& Lichten, W. (1951). The intelligibility of speech as a function of the context of the test materials. Journal of Experimental Psychology, 41(5), 329-335. https://doi.org/10.1037/h0062491

Mol, S. E., Bus, A. G., Jong, M. T. de, \& Smeets, D. J. H. (2008). Added value of dialogic parent-child book readings: A meta-analysis. Early Education and Development, 19(1), 7-26.

https://doi.org/10.1080/10409280701838603

Nabalek, A., \& Nabalek, I. (1985). Room acoustics and speech perception. In Handbook of Clinical Audiology. Williams \& Wilkins.

Nelson, P. B., Jin, S.-H., Carney, A. E., \& Nelson, D. A. (2003). Understanding speech in modulated interference: Cochlear implant users and normal-hearing listeners. The Journal of the Acoustical Society of America, 113(2), 961-968. https://doi.org/10.1121/1.1531983

Nematzadeh, A., Fazly, A., \& Stevenson, S. (2012). A Computational Model of Memory, Attention, and Word Learning. Proceedings of the 3rd Workshop on Cognitive Modeling and Computational Linguistics (CMCL 2012), 80-89. https://www.aclweb.org/anthology/W12-1708

Neuman, A. C., Wroblewski, M., Hajicek, J., \& Rubinstein, A. (2010). Combined effects of noise and reverberation on speech recognition performance of normal-hearing children and adults. Ear and Hearing, 31(3), 336-344. https://doi.org/10.1097/AUD.0b013e3181d3d514

Nielsen, E. G. (2015). The coffee shop effect: Investigating the relationship between ambient noise and cognitive flexibility.

Nippold, M., \& Haq, F. (1996). Proverb comprehension in youth: The role of concreteness and familiarity. Journal of Speech and Hearing Research, 39, 166-176.

Picard, M., \& Bradley, J. (2001). Revisting speech interference in classrooms. Audiology, 40, 221-244.

Plack, C. (2018). The Sense of Hearing.

Pollack, I. (1975). Auditory informational masking. Journal of the Acoustical Society of America, 57(S5).

Riley, K. G., \& McGregor, K. (2012). Noise hampers children's expressive word learning. Language, Speech, and Hearing Services in Schools, 43(3), 325-337. https://doi.org/10.1044/0161-1461(2012/110053)

Silvia, P. J., McCord, D. M., \& Gendolla, G. H. E. (2010). Self-focused attention, performance expectancies, and the intensity of effort: Do people try harder for harder goals? Motivation and Emotion, 34(4), 363-370. https://doi.org/10.1007/s11031-010-9192-7

Stelmachowicz, P., Hoover, B. M., Lewis, D. E., Kortekaas, R. W. L., \& Pittman, A. L. (2000). The relation between stimulus context, speech audibility, and perception for normal-hearing and hearing- 
impaired children. Journal of Speech, Language \& Hearing Research, 43(4), 902.

https://doi.org/10.1044/jslhr.4304.902

Stelmachowicz, P., Pittman, A. L., Hoover, B., \& Lewis, D. (2004). Novel word learning in children with normal hearing and hearing loss. Ear and Hearing, 25(1), 47-56.

Storkel, H., Armbrüster, J., \& Hogan, T. P. (2006). Differentiating phonotactic probability and neighborhood density in adult word learning. Journal of Speech, Language, and Hearing Research, 49(6), 1175-1192. https://doi.org/10.1044/1092-4388(2006/085)

Storkel, Komesidou, R., Pezold, M., Pitt, A., Fleming, K., \& Romine, R. (2019). The impact of dose and dose frequency on word learning by kindergarten children with developmental language disorder during interactive book reading. Language, Speech, and Hearing Services in Schools, 50(4), 518-539. https://doi.org/10.1044/2019_LSHSS-VOIA-18-0131

Watson, C. S., Kelly, W. J., \& Wroton, H. W. (1976). Factors in the discrimination of tonal patterns. II. Selective attention and learning under various levels of stimulus uncertainty. The Journal of the Acoustical Society of America, 60(5), 1176-1186. https://doi.org/10.1121/1.381220

Wiederholt, J., \& Bryant, B. R. (2012). Gray Oral Reading Test, 5th ed. (5th ed.). PRO-ED, Inc.

Wightman, F. L., \& Kistler, D. J. (2005). Informational masking of speech in children: Effects of ipsilateral and contralateral distracters. The Journal of the Acoustical Society of America, 118(5), 31643176. https://doi.org/10.1121/1.2082567

Woodcock, R. (1997). Woodcock Reading Mastery Tests-Revised (Normative Update). American Guidance Service.

Wróblewski, M., Lewis, D. E., Valente, D. L., \& Stelmachowicz, P. (2012). Effects of reverberation on speech recognition in stationary and modulated noise by school-aged children and young adults. Ear and Hearing, 33(6), 731-744. https://doi.org/10.1097/AUD.0b013e31825aecad

Yacullo, W. S., \& Hawkins, D. B. (1987). Speech recognition in noise and reverberation by school-age children. Audiology, 26(4), 235-246. https://doi.org/10.1080/00206098709081552 